ISSN: 0514-7336

DOI: https://doi.org/10.14201/zephyrus2016781933

\title{
ESTELA DECORADA EN EL DOLMEN DEL ALTO DE LA HUESERA (LAGUARDIA, ÁLAVA)
}

\section{Decorated stela in Alto de la Huesera dolmen (Laguardia, Álava)}

Javier Fernández-Eraso, Erik Arevalo-Muñoz, Cristina Camarero Arribas, Marcos García-Diez, Blanca Ochoa Fraile y José Antonio Mujika-Alustiza

Dpto. Geografía, Prehistoria y Arqueología. Facultad de Letras UPV-EHU. Cl Tomás y Valiente, s/n. 01006 Vitoria. Correo-e: javier.fernandeze@ehu.eus; earevalo002@gmail.com; cristina.camarero.a@gmail.com; marcos.garcia@ehu. eus; blanca.ochoafraile@gmail.com; joseantonio.mugica@ehu.eus

Recepción: 14/02/2016; Revisión: 6/07/2016; Aceptación: 31/07/2016

Resumen: El dolmen del Alto de la Huesera fue excavado en 1948. En 2010 se inició una intervención arqueológica con el fin de determinar el estado del monumento y su posterior puesta en valor. Durante estos trabajos se localizó una losa decorada de arenisca en el túmulo, junto al corredor, datable en el Calcolítico. Presenta cinco profundos surcos paralelos horizontales que se cierran en un extremo describiendo una forma acampanada y dos formas apuntadas que se relacionan con puñales de lengüeta. Esta nueva localización y la revisión de los grafismos postpaleolíticos del sector vasco-navarro documentan la diversidad gráfica en temas y contextos de este fenómeno artístico de la Prehistoria.

Palabras clave: Arte megalítico; Prehistoria Reciente; Calcolítico; Norte de España.

Aвstract: The Alto de la Huesera dolmen was excavated in 1948. In 2010 a new archaeological fieldwork started with the objective of determining the condition of the monument, subsequently restoring it. In these works the team located a sandstone stela in the burial mound and beside the corridor, datable to the Chalcolithic age. The engravings are five deep parallel grooves that come in contact at the end creating a bell-shaped form and two pointed shapes that are connected with a 'puñal de lengüeta'. This discovery and the revision of the post-Paleolithic graphic entities from the Basque-Navarre area allow the documentation of the graphic diversity, both in theme and context, of the artistic phenomenon of Prehistory.

Key words: Megalithic art; Recent Prehistory; Chalcolithic; Northern Spain.

\section{Introducción}

La geografía del arte megalítico peninsular se ha modificado en los últimos años (Bueno et al., 2009a, 2009b). El sector cántabro-pirenaico del norte de la Península Ibérica ha sido considerado un área geográfica en la que el grafismo estaba escasamente documentado en contextos megalíticos (Shee, 1981; De Balbín,

1 Esta labor de investigación se enmarca en el ámbito del Grupo de Investigación en Prehistoria de la UPV-EHU del Gobierno Vasco (IT-622/13), del proyecto HaR2011-26956 del Ministerio de Ciencia e Innovación y del proyecto El Megalitismo en Álava de la Diputación Foral de Álava. El trabajo de E. Arévalo, C. Camarero y B. Ochoa se ha desarrollado en el ámbito del Programa de Formación de Investigadores Pre-doctorales del Gobierno Vasco y de la UPV-EHU. 
1989; Bueno y De Balbín, 2003). Esta realidad se correspondía con la baja densidad de arte postpaleolítico en abrigos, cavidades y al aire libre (De Balbín, 1989; Gómez Barrera, 1992; Díaz, 1993; García-Diez y Hortolá, 2003). Además contrastaba con el mayor número de conjuntos gráficos en abrigos y al aire libre en zonas limítrofes (Gómez Barrera, 1992), si bien el arte megalítico representaba un vacío que progresivamente fue diluyéndose con la localización de monumentos megalíticos decorados en Castilla y León (Delibes y Rojo, 1988), Galicia (Bello, 1994), Euskadi y Navarra (López Quintana, 2007-2009; Bueno et al., 2005) y posteriormente en el centro del área cantábrica (De Blas, 1997).

Así, la ausencia de grafismo megalítico era una apariencia arqueológica, consecuencia de la carencia de proyectos que atendieran la perspectiva gráfico-simbólica, en parte por las dificultades para su reconocimiento. Sin embargo, también debe considerarse el estado de conservación de las cámaras de muchos monumentos, cuyos ortostatos están fragmentados o faltan debido a su reutilización.

La progresiva localización de grafismos en contextos megalíticos (Bueno et al., 2009b) ha supuesto una ruptura con la tradicional consideración de un arte megalítico propio de la fachada atlántica y del s-so peninsular. También se ha desdibujado (Bueno et al., 2008) la visión que implicó la definición de áreas geográficas -con implicaciones socioculturales-, que sirvieron para contraponer lo mediterráneo - con mayor recurso a la pintura- frente a lo atlántico -vinculado al grabado-, y cronológicas -tendencia a que lo pintado era anterior al grabado-. Además, la visión integrada de la comparación temática y de implantación espacial-megalítico, abrigos y aire libre- ha permitido proponer que una gran parte de la iconografía postpaleolítica forma parte de una misma estructura ideológica.

La Rioja Alavesa es un área clásica del Megalitismo peninsular por haberse llevado a cabo excavaciones desde el primer tercio de la pasada centuria, documentarse arquitecturas de grandes dimensiones

(C) Universidad de Salamanca y ajuares de gran calidad. A pesar de ello y de la alta densidad de arquitecturas funerarias, no se había documentado ninguna evidencia de arte megalítico, por lo que representaba un vacío en este sentido. El descubrimiento reciente de una estela decorada en el dolmen del Alto de la Huesera completa la dispersión del arte megalítico, relativizando la existencia de vacíos geográficos. En el presente trabajo se describe la decoración del soporte, se valora su cronología y se inscribe en el contexto del fenómeno gráfico megalítico del sector geográfico circundante.

\section{El dolmen del Alto de la Huesera}

Se localiza en la Rioja Alavesa (Fig. 1), comarca que se enmarca entre las sierras de Codes y Cantabria-Tolońo y el cauce del río Ebro, formando parte de la Depresión del Ebro. La altura máxima de la sierra alcanza $1440 \mathrm{~m}$, siendo la cota mínima $900 \mathrm{~m}$. Esta característica hace que la sierra actúe a modo de barrera bioclimática, separando lo mediterráneo -al s- de lo atlántico -al N-.

Al pie de la Sierra de Cantabria y hasta el cauce del río Ebro dominan los planos inclinados hacia el $s$ con suaves pendientes que unen las tierras elevadas, al pie de monte de la sierra, con las más próximas al río. Existen altozanos cuyas alturas oscilan entre 580 y 690 m y otras zonas de superficies más bajas comprendidas entre los 420 y $440 \mathrm{~m}$.

\subsection{Contexto arqueológico}

En el sector geográfico en el que se ubica el dolmen se documenta una intensa ocupación humana desde el Neolítico Antiguo a época romana. El dolmen del Alto de la Huesera (Fig. 1) fue descubierto por Domingo Fernández Medrano en 1947 y excavado, por él mismo, al ańo siguiente (Fernández Medrano, 1948; Barandiarán y Fernández Medrano, 1958). En 2010 se inició un proyecto de excavación y estudio dirigido por J. A. Mujika y J. Fernández-Eraso $(2011,2012,2013,2014)$. 

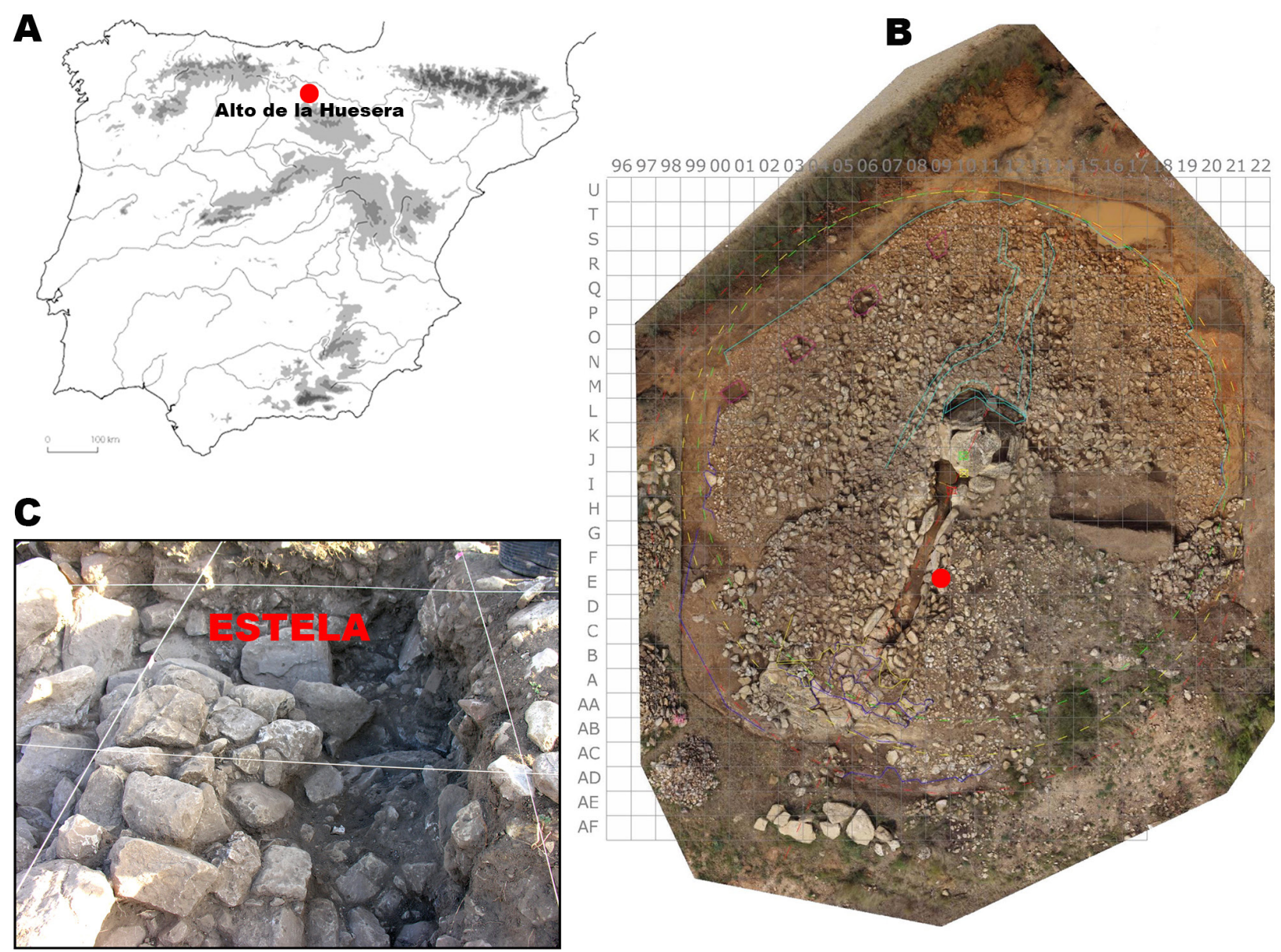

D

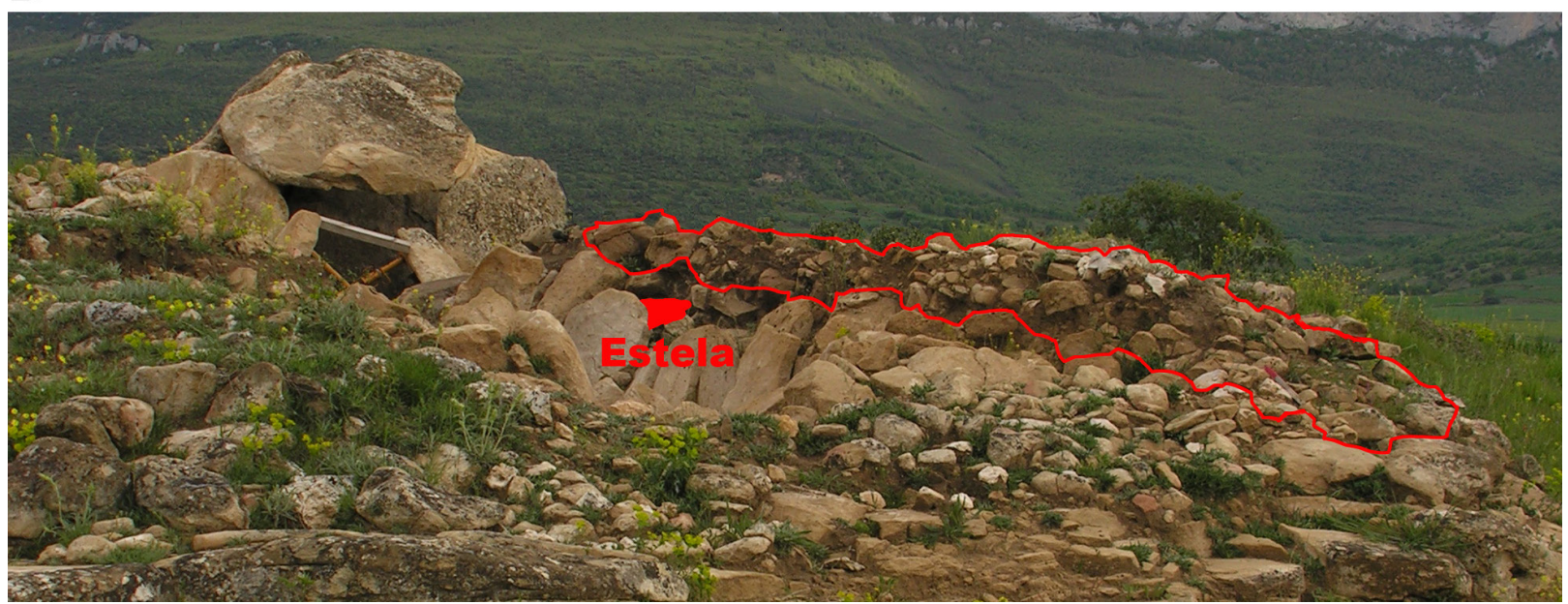

Fig. 1. El dolmen del Alto de la Huesera: A) localización geográfica; B) ortoimagen del dolmen con indicación de la localización de la estela decorada; $C$ ) detalle fotográfico del descubrimiento de la estela; D) vista de sección transversal con implantación de la estela en relación al morcuero. 
El proyecto se centró inicialmente en la cámara, con la extracción de la cubierta caída y su posterior excavación, ya que se pudo constatar que parte del depósito sepulcral se encontraba intacto. Durante las campańas de 2010 y 2011 se recuperaron, en un nivel de unos $40 \mathrm{~cm}$, restos humanos -algunos en conexión anatómica y el número mínimo es de al menos 106 (Fernández Crespo y Rúa, 2015)-, además de abundante ajuar. El equipamiento material es variado. En la industria lítica destacan 1 trapecio de retoque abrupto, 10 puntas de flecha-de pedúnculo y apéndices laterales, de pedúnculo y aletas desarrolladas, etc.- con retoque plano bifacial, 3 láminas de hoz completas de tamaño destacado $\rightarrow>6 \mathrm{~cm}-$, otros 3 fragmentos mediales y 1 raspador. Entre los adornos destacan las cuentas discoidales biseladas -tipo arandelas- de hueso, cuentas tipo tonelete en distintas rocas -calcita, lignito, etc.- y 1 concha perforada. El conjunto cerámico incluye campaniformes y cordadas. En bronce destacan un punzón o biapuntado y una punta de flecha de pedúnculo y aletas.

Las zanjas superficiales abiertas en el túmulo documentaron que era circular $-\mathrm{y}$ no ovalado como inicialmente se había propuesto-, que había sido construido con bloques de arenisca y caliza -estas últimas en su superficie más exterior- y que alcanzaba un diámetro de unos $20 \mathrm{~m}$ y una potencia variable -entre aproximadamente 1 y 2 m-.

A pesar de no haberse documentado en los primeros trabajos, se localizó un corredor delimitado por varios ortostatos e in situ una losa de cubierta. Su longitud es de unos $8 \mathrm{~m}$ y su anchura varía entre 1 y $1,20 \mathrm{~m}$.

Las dataciones $\mathrm{C}^{14}$ (Fig. 2) muestran un uso dilatado de la estructura funeraria entre hace $4520 \pm$ 30 вр (Beta-301219; 5310-5050 cal вр) у 3550 \pm 30 вр (Beta-321417; 3958-3721 cal вр). El momento fundacional correspondería, cuando menos, al Calcolítico inicial, si bien no debiera descartarse una fase final del Neolítico debido a la presencia de una armadura geométrica. Se documenta un uso reiterado del monumento durante el Calcolítico Medio-Final, la fase campaniforme, el Bronce Inicial y un momento avanzado del Bronce.

\begin{tabular}{|c|c|c|c|c|}
\hline Dolmen & Fecha BP & Fecha cal BC $(2 \sigma)$ & Material muestra & Laboratorio \\
\hline El Sotillo & $2740 \pm 30$ & $930 / 820$ & hueso humano & Beta 299308 \\
\hline El Sotillo & $3120 \pm 30$ & $1440 / 1370-1340 / 1320$ & hueso humano & Beta 299303 \\
\hline El Sotillo & $3160 \pm 30$ & $1500 / 1400$ & hueso humano & Beta 299307 \\
\hline La Chabola de la Hechicera & $3170 \pm 130$ & $1750 / 1110$ & hueso humano & \\
\hline La Chabola de la Hechicera & $3280 \pm 40$ & $1650 / 71460$ & hueso humano & Beta 288936 \\
\hline El Sotillo & $3320 \pm 30$ & $1680 / 1520$ & hueso humano & Beta 299309 \\
\hline El Sotillo & $3360 \pm 30$ & $1740 / 1600-1570 / 1540$ & hueso humano & Beta 299312 \\
\hline El Sotillo & $3360 \pm 30$ & $1740 / 1600-1570 / 1540$ & hueso humano & Beta 299302 \\
\hline El Sotillo & $3380 \pm 30$ & $1740 / 1610$ & hueso humano & Beta 299311 \\
\hline El Sotillo & $3430 \pm 30$ & $1870 / 1850-1780 / 1670$ & hueso humano & Beta 299101 \\
\hline El Sotillo & $3550 \pm 30$ & $1960 / 1870-1850 / 1780$ & hueso humano & Beta 299310 \\
\hline Alto de la Huesera & $3550 \pm 30$ & $1950 / 1870-1840 / 1810-1800 / 1780$ & hueso humano & Beta 321417 \\
\hline Layaza & $3770 \pm 30$ & $2290 / 2130-2080 / 2060$ & hueso humano & Beta 317864 \\
\hline Alto de la Huesera & $3850 \pm 30$ & $2460 / 2200$ & hueso humano & Beta 321418 \\
\hline El Montecillo & $3920 \pm 40$ & $2550 / 2540-2490 / 2290$ & hueso humano & Beta 288932 \\
\hline El Sotillo & $4000 \pm 40$ & $2610 / 2600-2590 / 2460$ & hueso humano & Beta 299300 \\
\hline Alto de la Huesera & $4010 \pm 30$ & $2580 / 2470$ & hueso humano & Beta 321414 \\
\hline El Sotillo & $4040 \pm 30$ & $2630 / 2480$ & hueso humano & Beta 299306 \\
\hline Alto de la Huesera & $4050 \pm 30$ & $2830 / 2820-2660 / 2650-2630 / 2490$ & hueso humano & Beta 321419 \\
\hline Layaza & $4060 \pm 30$ & $\begin{array}{c}2830 / 2820-2660 / 2640-2640 / 256-2560 / 2550- \\
2540 / 2490\end{array}$ & hueso humano & Beta 317862 \\
\hline Alto de la Huesera & $4080 \pm 30$ & $2850 / 2810-2740 / 2720-2700 / 2570-2520 / 2500$ & hueso humano & Beta 321415 \\
\hline
\end{tabular}




\begin{tabular}{|c|c|c|c|c|}
\hline Dolmen & Fecha BP & Fecha cal BC $(2 \sigma)$ & Material muestra & Laboratorio \\
\hline Los Llanos & $4080 \pm 170$ & $3100 / 2000$ & hueso humano & I 15195 \\
\hline Los Llanos & $4090 \pm 120$ & $2950 / 2300$ & hueso humano & I 14593 \\
\hline Alto de la Huesera & $4100 \pm 30$ & $2860 / 2810-2760 / 2720-2700 / 2570-2510 / 2500$ & hueso humano & Beta 321420 \\
\hline San Juan APL 4 & $4200 \pm 95$ & $3022 / 2493$ & hueso humano & \\
\hline Alto de la Huesera & $4230 \pm 30$ & $2900 / 2865-2805 / 2760$ & hueso humano & Beta 391716 \\
\hline Alto de la Huesera & $4290 \pm 30$ & $2920 / 2880$ & hueso humano & Beta 301226 \\
\hline Alto de la Huesera & $4300 \pm 30$ & $2920 / 2880$ & hueso humano & Beta 301224 \\
\hline Alto de la Huesera & $4320 \pm 30$ & $3010 / 2980-2960 / 2950-2940 / 2890$ & hueso humano & Beta 321416 \\
\hline Alto de la Huesera & $4320 \pm 30$ & $3010 / 2970-2960 / 2890$ & hueso humano & Beta 301223 \\
\hline Alto de la Huesera & $4320 \pm 30$ & $3010 / 2970-2960 / 2890$ & hueso humano & Beta 301221 \\
\hline Alto de la Huesera & $4340 \pm 30$ & $3020 / 2900$ & hueso humano & Beta 301220 \\
\hline Alto de la Huesera & $4350 \pm 30$ & $3020 / 2900$ & hueso humano & Beta 301222 \\
\hline El Sotillo & $4350 \pm 30$ & $3020 / 2900$ & hueso humano & Beta 299305 \\
\hline Layaza & $4360 \pm 30$ & $3080 / 3060-3030 / 2060$ & hueso humano & Beta 317863 \\
\hline La Chabola de la Hechicera & $4380 \pm 40$ & $3100 / 2900$ & hueso humano & Beta 288933 \\
\hline Alto de la Huesera & $4390 \pm 30$ & $3090 / 2910$ & hueso humano & Beta 301225 \\
\hline El Sotillo & $4390 \pm 30$ & $3090 / 2910$ & hueso humano & Beta 299304 \\
\hline Alto de la Huesera & $4410 \pm 30$ & $3260 / 3245-3100 / 2920$ & hueso humano & Beta 391717 \\
\hline La Chabola de la Hechicera & $4420 \pm 30$ & $3310 / 3300-3280 / 3280-3260 / 3240-3100 / 2920$ & hueso humano & Beta 307797 \\
\hline La Chabola de la Hechicera & $4430 \pm 40$ & $3330 / 3210-3180 / 3150-3130 / 2920$ & hueso humano & Beta 288939 \\
\hline Alto de la Huesera & $4430 \pm 30$ & $3320 / 3235-3170 / 3160-3115 / 3005-2990 / 2930$ & hueso humano & Beta 382978 \\
\hline San Juan APL 2 & $4440 \pm 40$ & $3334 / 2926$ & hueso humano & \\
\hline La Chabola de la Hechicera & $4440 \pm 40$ & $3340 / 3210-3190 / 2920$ & hueso humano & Beta 288937 \\
\hline Alto de la Huesera & $4450 \pm 30$ & $3330 / 3215-3185 / 3155-3130 / 3015$ & hueso humano & Beta 382979 \\
\hline San Juan APL 8 & $4460 \pm 70$ & $3351 / 2927$ & hueso humano & \\
\hline Alto de la Huesera & $4470 \pm 30$ & $3340 / 3080-3070 / 3025$ & hueso humano & Beta 382980 \\
\hline La Chabola de la Hechicera & $4480 \pm 40$ & $3350 / 3020$ & hueso humano & Beta 288934 \\
\hline San Juan APL 1 & $4510 \pm 40$ & $3361 / 3091$ & hueso humano & \\
\hline San Juan APL 5 & $4520 \pm 50$ & $3366 / 3031$ & hueso humano & \\
\hline San Juan APL 7 & $4520 \pm 75$ & $3497 / 2933$ & hueso humano & \\
\hline Alto de la Huesera & $4520 \pm 30$ & $3360 / 3100$ & hueso humano & Beta 301219 \\
\hline San Juan APL 3 & $4570 \pm 40$ & $3496 / 3103$ & hueso humano & \\
\hline La Chabola de la Hechicera & $4650 \pm 40$ & $3610 / 3610-3520 / 3360$ & hueso humano & Beta 288938 \\
\hline San Martín & $4650 \pm 30$ & $3520 / 3390-3390 / 3369$ & hueso de punzón & Beta 339342 \\
\hline Los Llanos & $4660 \pm 200$ & $4000 / 2800$ & hueso humano & I 14788 \\
\hline La Chabola de la Hechicera & $4670 \pm 40$ & $3620 / 3590-3530 / 3360$ & hueso humano & Beta 288935 \\
\hline San Martín & $4780 \pm 31$ & $3643 / 3518$ & hueso humano & OxA-X 2626-36 \\
\hline San Martín & $4800 \pm 40$ & $3640 / 3550-3540 / 3370$ & hueso humano & Beta 273269 \\
\hline San Martín & $4806 \pm 34$ & $3654 / 3619-3610 / 3522$ & hueso humano & OxA-X 2627-25 \\
\hline La Chabola de la Hechicera & $4980 \pm 30$ & $3890 / 3880-3800 / 3700$ & carbón & Beta 307796 \\
\hline San Martín & $4896 \pm 32$ & $3761 / 3742-3731 / 3726-3715 / 3637$ & hueso humano & OxA-X 2627-24 \\
\hline San Juan APL 85 A & $5020 \pm 140$ & $4229 / 3522$ & hueso humano & \\
\hline San Juan APL 85 B & $5070 \pm 150$ & $4255 / 3535$ & hueso humano & \\
\hline Los Llanos & $5190 \pm 120$ & $4350 / 3700$ & hueso humano & I 15168 \\
\hline San Martín & $5380 \pm 40$ & $4330 / 4220-4210 / 4160--4130 / 4060$ & hueso ídolo espátula & Beta 339342 \\
\hline San Martín & $5920 \pm 40$ & $4900 / 4860-4850 / 4710$ & hueso ídolo espátula & Beta 317865 \\
\hline
\end{tabular}

Fig. 2. Dataciones de los niveles de ocupación del dolmen del Alto de la Huesera y de otros yacimientos dolménicos citados en el texto (APL: Ante Portam Latinam) (Fernández-Eraso y Mujika-Alustiza, 2013). 


\subsection{La estela decorada}

En el exterior de las losas 5 y 6 del corredor, a poco más de $1 \mathrm{~m}$ y sobre la superficie del túmulo original, se identificó una estela con decoración grabada que se encontraba apoyada sobre uno de sus laterales y bajo una potente capa de bloques -unos $45 \mathrm{~cm}$ - acumulados, a modo de morcuero, en época posterior a la construcción del túmulo original (Fig. 1D). Espacialmente se localizó en el extremo del corredor intratumular, antes de la zona adintelada del mismo. Aunque su posición tumbada no sea muy posiblemente la original, su localización no debiera estar muy alejada de su emplazamiento primigenio.

El soporte decorado (Fig. 1А у в) es una losa de arenisca pseudotriangular de $47,5 \mathrm{~cm}$ de altura máxima, $43,5 \mathrm{~cm}$ de anchura máxima y $14 \mathrm{~cm}$ de grosor medio; sus dimensiones están dentro de la variabilidad de las lajas de la base del túmulo, a la vez que son mayores que las de la capa superficial del mismo. Esta roca forma parte del substrato arenisco de la zona y se corresponde con el mismo tipo utilizado para los ortostatos y la cubierta. Presenta las caras en general planas, si bien en la decorada un resalte natural rompe la uniformidad de la superficie. No se han identificado acciones técnicas conducentes a la preparación de las superficies y bordes.

Los tres motivos o unidades gráficas se identifican en una misma cara del soporte. En la parte inferior un motivo envolvente tipo 'acampanado' configurado a partir de cinco líneas rectilíneas paralelas - la discontinuidad del trazado de algunas se debe a desconchados producidos tras el proceso de grabado-; mide $34,5 \mathrm{~cm}$ de ancho y $14,5 \mathrm{~cm}$ de alto. Las líneas fueron ejecutadas por percusión y presentan una anchura variable entre 4 y $20 \mathrm{~mm}$, siendo los surcos muy profundos.

Por encima de ésta se grabaron, en la parte central del soporte y en un pequeño resalte central, dos formas apuntadas. La primera corresponde a la morfología de punta triangular asimétrica -escaleno y acutángulo- con apéndice lateral incipiente y arranque de pedúnculo. Presenta unas medidas máximas de $7,5 \mathrm{~cm}$ de ancho y $14,5 \mathrm{~cm}$ de alto.
Se documentan dos técnicas: el trazo simple, fino y poco profundo, y la percusión que configura líneas de anchura variable entre 2 y $8 \mathrm{~mm}$, siendo los surcos poco profundos. La relación entre ambos procedimientos técnicos implica que el grabado fino es anterior a la percusión y que el primero se utilizó para esbozar la morfología general apuntada.

La segunda morfología apuntada, situada a la izquierda de la anterior y de menor tamaño, es una forma romboidal con arranque de pedúnculo recto. Presenta unas medidas máximas de $2,5 \mathrm{~cm}$ de ancho y $5,5 \mathrm{~cm}$ de alto. Se grabó mediante trazo simple, muy fino y muy poco profundo. $\mathrm{Su}$ reconocimiento es muy complejo debido a la finura de la línea incisa y a la alteración superficial de la roca.

Cabe indicar la posibilidad de que el resalte de la cara decorada (Fig. 1c), localizado en la parte central, pudiera haberse integrado como parte del dispositivo iconográfico. De este modo, su forma pudiera relacionarse con un tipo de alabarda. Más allá del resalte, en apariencia natural, se reconocen, no sin problemas de identificación debido a la deficiente conservación de las superficies, varias pequeñas concavidades en la parte izquierda -y asociadas al borde del resalte- que pudieran vincularse a negativos de impacto producidos por un instrumento. Además, su relación física con la forma de líneas "acampanadas" pudiera llevar a interpretar ésta como una simplificación de una mano, motivo que se documenta esquemáticamente en algunas estelas decoradas de la geografía peninsular ${ }^{2}$ (Díaz-Guardamino, 2010). Sea como fuera, asumimos la dificultad -por falta de reconocimiento evidente y reiterado de acciones técnicas- de aceptar taxativamente la hipótesis formal del relieve natural, quedando por ello en una consideración basada en una percepción sugestiva.

Por último, consideramos que su forma actual correspondería con su configuración original, ya que no se han documentado evidencias de fracturas modernas y, además, las líneas que conforman la forma 'acampanada' no alcanzan el borde

2 Díaz-Guardamino, M.: Las estelas decoradas en la Prehistoria de la Península Ibérica. Tesis doctoral inédita presentada en 2010 en la Univ. Complutense de Madrid. 

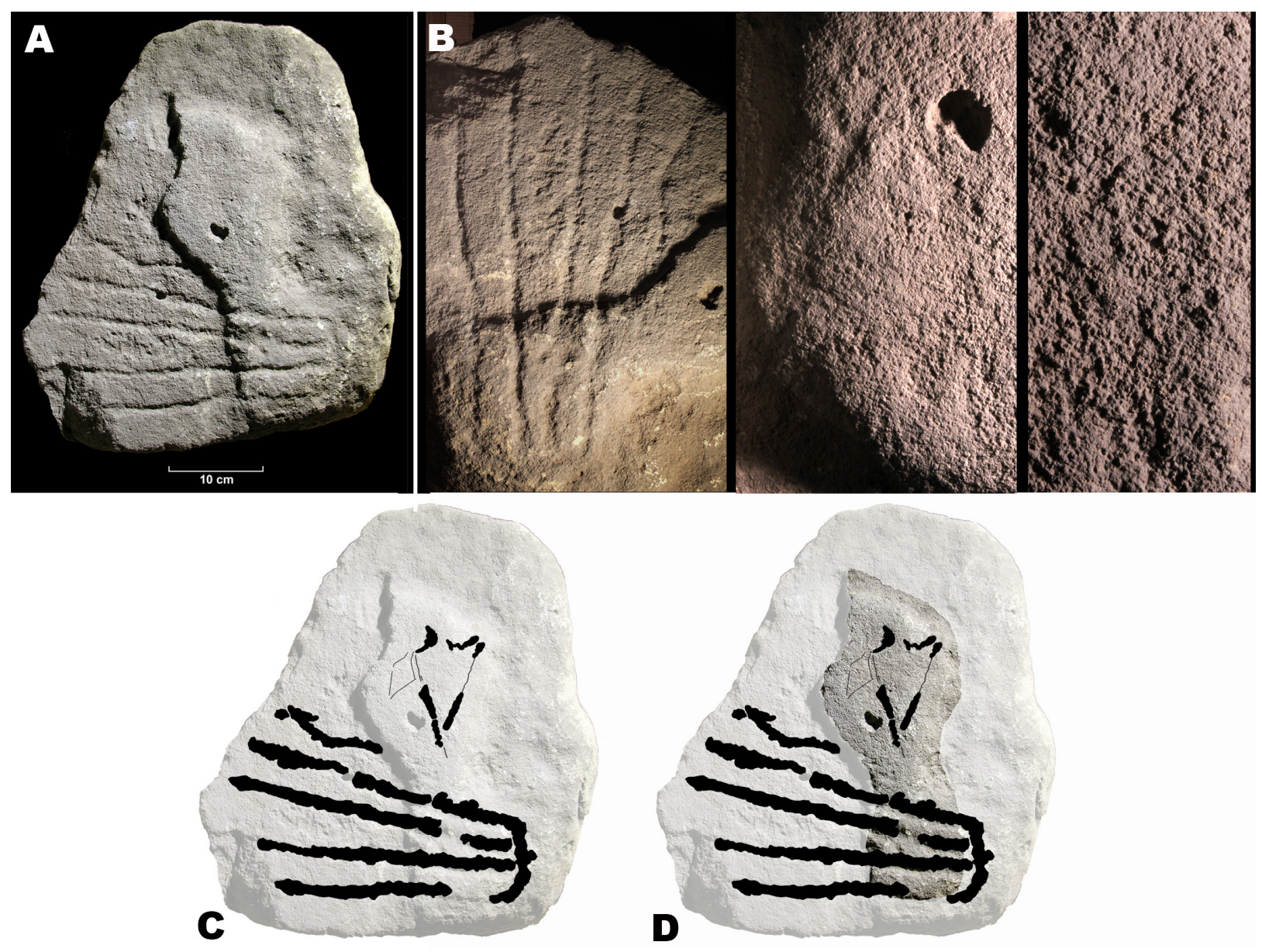

FIG. 3. La estela decorada del dolmen del Alto de la Huesera: A) imagen general; B) detalles de los motivos; C) calcos-morfologias grabadas-; D) propuesta de aprovechamiento de las cualidades formales del soporte.

izquierdo y todas se separan del mismo a una distancia similar.

Como se apuntó, la estela no estaría colocada en la base del túmulo, sino en su parte superior y en correspondencia con la parte superior de los ortostatos del corredor. Su implantación pudiera ser interpretada como un elemento de monumentalización y referenciación paisajística, pero su 'pequeño tamaño' implicaría que su visualización -y lecturasolo podría llevarse a cabo desde un contexto espacial inmediato y cercano al propio monumento. Por otro lado, la localización de la estela en la parte superior del túmulo implica una significación vinculable a todo el monumento, pero es difícil discriminar si su ejecución -y uso- tuvo un carácter individual -relativa a un individuo concreto- o colectivo -a los individuos asociados a la última fase de inhumación-; sea como fuere, su implantación y la reutilización del monumento pudieran implicar un valor atemporal del uso y significación de la estela, que progresivamente pudo haber sido reaprovechada.

\section{Discusión}

\subsection{Cronología de la decoración de la estela}

La frecuentación humana del dolmen, que se corresponde con un periodo máximo de casi 1600 años, entre hace 5310 y $3720 \mathrm{cal}$ вP, permite definir 
una fecha post-quem (edad máxima) de la ejecución, es decir, sincrónica o posterior a la segunda mitad del vi milenio cal вр. Por el contrario, es complicado aceptar la fecha más reciente como necesariamente límite ante-quem-edad mínima-, ya que una vez construida la estructura en cualquier momento pudiera haberse visitado y procedido al grabado de la iconografía, si bien hay que señalar que no se han documentado para el caso concreto frecuentaciones humanas posteriores a la primera mitad del IV milenio cal вр.

Durante los trabajos de excavación se atestiguaron dos momentos diferentes de utilización de la cámara. El más antiguo, que se corresponde con las excavaciones realizadas desde el año 2010 , se enmarca entre 5310 y 4830 cal BP. El de cronología más reciente se identifica, básicamente, con las intervenciones de 1948 y se desarrolla entre 4450 y $3720 \mathrm{cal}$ BP. En la zona del corredor más próxima a la cámara se obtuvo una datación de 5210-5195 cal вP. Así el corredor y la parte baja de la cámara muestran una cronología similar, lo que no ocurre en la parte alta de la cámara, de cronología más reciente. La primera ocupación obedece al momento fundacional del dolmen, que se prolonga hasta el colapso del mismo. La segunda a la modificación de la arquitectura en la zona de la cámara, la amortización del corredor y su
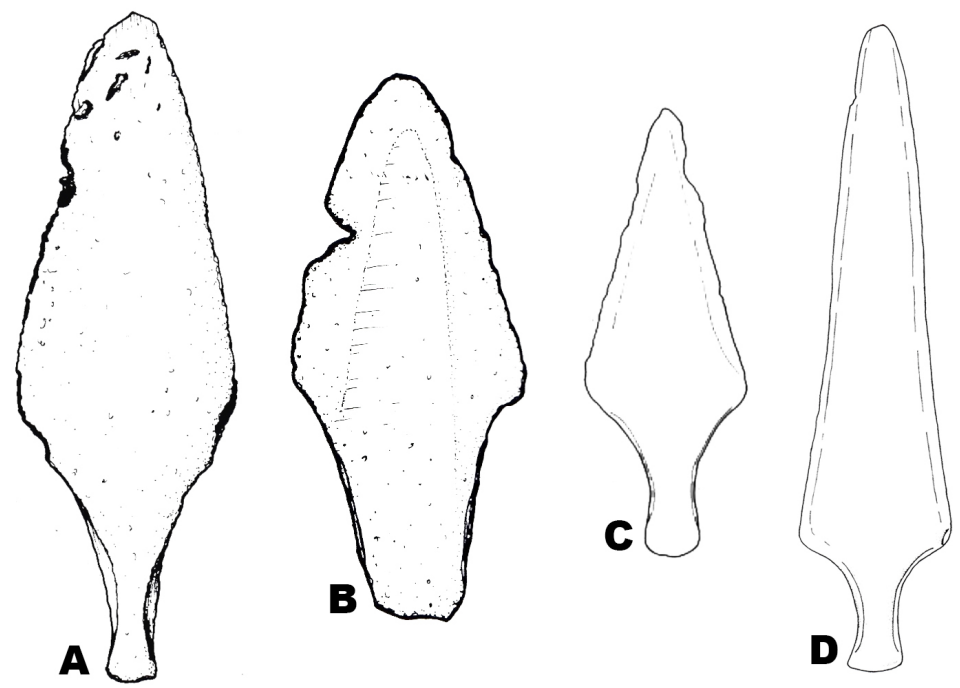

FIG. 4. Puñales de lengüeta: A) Obioneta Sur; B) Goldanburu; C) Puerto de Herrera y D) San Martin (según Fariña, 1966 y Apellániz, 1973; sin escala). reutilización a modo de dolmen simple hasta el definitivo abandono de la estructura funeraria.

Dos de los temas figurativos de la estela son morfologías apuntadas. A pesar de este carácter común, su variabilidad es destacada: forma general triangular o romboidal, ausencia de apéndices laterales o incipiente en un lateral, y pedúnculo desarrollado recto o escasamente incipiente. Destacan sus diferentes dimensiones, variabilidad que bien pudiera responder a una transposición fidedigna de la realidad material, o bien, como probablemente sea más correcto considerar, a una voluntad artística en la que la finalidad gráfica se centra en transmitir el concepto principal -el carácter apuntado-. Estas morfologías se asemejan a un puñal de lengüeta, como los documentados en el contexto cercano de Obioneta Sur (Fig. 4A; Apellániz, 1973: 263) o Goldanburu (Fig. 4B; Aranzadi y Barandiarán, 1953: 95), ambos de cronología Calcolítico Final-Bronce Antiguo (Rodríguez de la Esperanza, 2005: 78).

La de mayor dimensión presenta morfología triangular y hoja desproporcionadamente ancha. En el extremo proximal se ha querido representar un apéndice que desde el punto de vista tipológico se correspondería con una lengüeta. Podría tratarse de un puñal ancho de lengüeta, de los cuales hay paralelos próximos: en el Puerto de la Herrera (Fig. 4C; Apellániz, 1973) y en el nivel superior del dolmen de San Martín (Fig. 4D; Barandiarán y Fernández Medrano, 1964; Apellániz, 1973), junto a botones de perforación en $\mathrm{v}$ y cerámica campaniforme que apuntan a una cronología del Calcolítico Final. Pero para esta morfología también sería susceptible de considerar la representación de una alabarda, aunque la falta de algunos detalles - como la nervadura central- dificulta aceptar dicho reconocimiento.

En conclusión, y a partir de las comparaciones propuestas, la cronología de las morfologías grabadas habría que situarla en un lapso cronológico de entre aproximadamente 5050 y 4450 
cal вр, еs decir, en el Calcolítico Final. Considerando que el estudio global del megalitismo ibérico permite confirmar, con carácter genérico, una clara tendencia a relacionar una "contemporaneidad esencial entre la construcción y la decoración" (Bueno et al., 2007: 636), cabría plantear como hipótesis más probable que la decoración de la estela se llevó a cabo en el momento en el que se realizó algún tipo de transformación arquitectónica, habilitar un nuevo acceso por la parte este de la cámara. Durante la excavación del monumento se constató el temprano abandono del uso del corredor, junto al que se recuperó la estela, y la clausura intencional del mismo para continuar utilizando sólo la cámara. Este fenómeno se relaciona con las fechas obtenidas en la cámara, que definen un lapso de unos 200 años en los que, al parecer, no se efectuaron inhumaciones entre el $4300 \pm 30$ вр (Beta 301224; 4880-4830 cal вр) у $4100 \pm 30$ вр (Beta 321415 ; 4810-4760 у 4460-4450 cal вг), fecha a partir de la que se observa un aumento de las inhumaciones.

\subsection{Arte postpaleolitico en el entorno del dolmen del Alto de la Huesera}

El contexto gráfico de la estela del dolmen del Alto de la Huesera se circunscribe a la geografía vasco-navarra, con una diversidad de modalidades de expresión gráfica (Fig. 5).

En contextos megalíticos se cuenta con evidencias antropomorfas, bien en soportes mobiliares de hueso, bien sobre bloques pétreos a modo de estelas. Entre los primeros se pueden señalar los ídolos espátula con representaciones femeninas, sobre tibias de ovicaprino, recuperados en dólmenes como el de San Martín, datados en $5920 \pm 40$ y $5380 \pm 40$ BP, cuyos paralelos se localizan en dólmenes como El Miradero, La Velilla y otros (Fernández-Eraso et al., 2015) ${ }^{3}$.

Cf. también Zapatero, M. P. (2015): El Neolitico en el noreste de la cuenca del Duero: el yacimiento de La Velilla en el valle del Valdavia (Palencia). Tesis doctoral presentada en 2015 en la Univ. de Valladolid (disponible en https://www.uvadoc.uva.es/bitstream/10324/13185/1/Tesis695-150729.pdf [acceso 11/07/2016]).
Por lo que al segundo caso se refiere, en los dólmenes de Errekatxuetako Atxa (López Quintana y Guenaga, 2007/2009; Bueno et al., 2007/2009; López Quintana et al., 2010) y Mendigana (Bueno et al., 2007/2009). Asimismo en la estructura hemisférica megalítica tipo cista de Katillotxu v (López Quintana y Guenaga, 2007/2009; Bueno et al., 2007/2009; López Quintana et al., 2010) se documentó una variada actividad gráfica, alguna sobre estela antropomorfa: una punta pedunculada tipo Palmela, un útil enmangado -posiblemente hacha-, pequeños círculos y/o cazoletas, un motivo interpretado como pieza doble tipo pulimento, una forma concéntrica tendente a triangular, una banda de cinco líneas paralelas enmarcada por un reborde oval, una forma oval con división interna, otras semicirculares y diversas líneas. A estas localizaciones se añade el aquí presentado y además se ha indicado la existencia de un dolmen con pinturas en Turendo (Bueno et al., 2007/2009: 43). Problemáticas son las líneas del menhir de Erroldan Harria (Iturralde y Suit, 1911: 202) y las posibles incisiones del dolmen de Argonitz (Apellániz, 1973).

Otros soportes trabajados sumariamente para definir formas gráficas son las estelas antropomorfas asociadas a construcciones megalíticas. En este contexto se consideraría el dolmen de Larrarte (Mujika y Armendáriz, 1991) y el de San Martín (Barandiarán y Fernández, 1971; Galilea, 2009), no existiendo consenso en este último sobre el carácter antropomorfo de las losas (Narvarte, 2005; López Quintana et al., 2010), que también se ha reconocido en el contorno trabajado del gran menhir de Kurtzegan (López Quintana, 2015).

La concepción de estela antropomorfa se ha descrito claramente para la estela-menhir de Soalar (Bueno et al., 2005), cuya complejidad gráfica se manifiesta por la presencia de un cinturón, de posibles protecciones pectorales asociadas a una armadura, una alabarda, etc., que implican su interpretación como de hombre armado o guerrero.

Una situación particular corresponde a la estela de Cortecampo iI (Ramos, 2007), una losa triangular, dispuesta a modo de señalización de una inhumación individual tipo hoyo, cuya decoración consiste en una banda roja en torno a la estela. 
La modalidad de abrigo pintado se documenta en Las Yurdinas II, Socuevas, Peña del Cantero I y II y Peña del Cuarto. En el primero (Fernández-Eraso, 2003; García-Diez y Hortolá, 2003), y asociado a un contexto de cueva sepulcral, se documenta una figura de bóvido y una mujer de trazado subnaturalista. En Socuevas (Llanos y Vegas, 2009) se identificaron motivos rojos -antropomorfos esquemáticos (uno con brazo en asa, otro con posible arco) y pequeñas líneas- y negros - principalmente de carácter lineal y grabados (rectángulos, reticulados, etc.)-, además de algún grabado histórico. En La Peńa del Cantero i (Santesteban, 1969, 1971) se han seńalado dos caprinos y una representación humana. En La Peña del Cantero II (Armendáriz et al., 1987) se han identificado, todo en rojo, una forma rectangular, varias líneas o barras y una problemática figura humana tipo ancoriforme. En La Peña del Cuarto (Monreal, 1977) se grabaron diversos trazos lineales y zoomorfos y figuras humanas simplificadas que se sitúan sobre el lomo de alguno de los zoomorfos, remitiendo la composición a un caballero. Por último, se ha señalado la existencia de pinturas rojas prehistóricas en el abrigo del Portillo de Lerón (Llanos, 2007), pero consideramos (por su carácter sobrexpuesto al exterior, por la posición de las pinturas sobre líquenes 'recientes' -en relación a una visita en 2005- y por el hecho de que actualmente están prácticamente perdidas) que no son dibujos de época prehistórica.

También se han documentado en el interior de cavidades, como en Ciriza (Nuin, 1988/1989), donde junto a dos formas de signos - uno lineal y otro geométrico- se ha reconocido un zoomorfo esquemático de extremidades y cuello alargados. Otro espacio subterráneo con representaciones grabadas es la cueva de Goikolau (Basas, 2000/01/02), donde se han identificado numerosas líneas, un conjunto de antropomorfos -posiblemente uno con los brazos en asa y otro tipo cruciforme- y al menos cinco zoomorfos (destacando los caprinos). Incluso para el interior de algunas cuevas -Solacueva, Lazalday, Los Moros, Liciti, Pico Corral, etc. - se propuso la existencia de una tradición gráfico-simbólica (principalmente de carácter lineal y en ocasiones

(C) Universidad de Salamanca figurativa, aunque su definición formal en varios casos es problemática) de la Edad del Bronce y del Hierro y denominada Arte Esquemático-Abstracto (Llanos, 1966, 1977); actualmente las fechas AMs $\mathrm{C}^{14}$ obtenidas determinan resultados de momentos prehistóricos y principalmente históricos, y su finalidad artístico-simbólica no es fácil de justificar (García-Diez y González, 2003).

Otros grafismos se emplazan en soportes naturales localizados en entornos de aire libre. Para Añorbe, Elizarrate, Nequeas, Learza, etc. (Monreal, 1977; Armendáriz, 1987) se han descrito cazoletas $\mathrm{u}$ hoyos de contorno preferentemente circular o pseudocircular que en algunos casos presentan surcos asociados, a modo de canales. También se han documentado cazoletas en losas cercanas espacialmente a contextos megalíticos: como en Jentillarri (Barandiarán et al., 1918) e Intxusburu (Barandiarán, 1975). Su adscripción cronológica es problemática, ya que, si bien existe una tendencia a vincularlas a momentos finales de la Prehistoria, no debe descartarse su edad histórica.

Descontextualizadas se encuentran las losas grabadas con motivos lineales rectilíneos paralelos o de óvalos concéntricos de Beire y Borunda (Mendoza, 1922; Beguiristáin y Jusué, 1986, 1987). Como se ha apuntado, posiblemente su origen se debe relacionar con ortostatos de monumentos megalíticos - ¿acaso menhires? como señala Mendoza (1922) - o con estelas. Igualmente poco seguro es el contexto arqueológico y de implantación de la laja o estela de Echauri (Beguiristáin, 1983; Nuin, 1988/1989), que presenta, en pintura negra y roja, puntos y líneas, y junto a ellos formas que pudieran interpretarse como zoomorfos -como una posible ave y formas pectiniformes que algunos autores (Acosta, 1968) vinculan con esquematizaciones de zoomorfos-, además de una posible herradura.

En el poblado Basagain, en un contexto habitacional que ha servido para sugerir de forma preliminar que se trata de un taller de estelas de finalidad funeraria del Bronce Final/Edad del Hierro, se ha señalado la existencia de losas y lajas con decoración lineal y formas reticuladas (Peñalver, 2009). Composiciones gráficas similares en contextos domésticos 


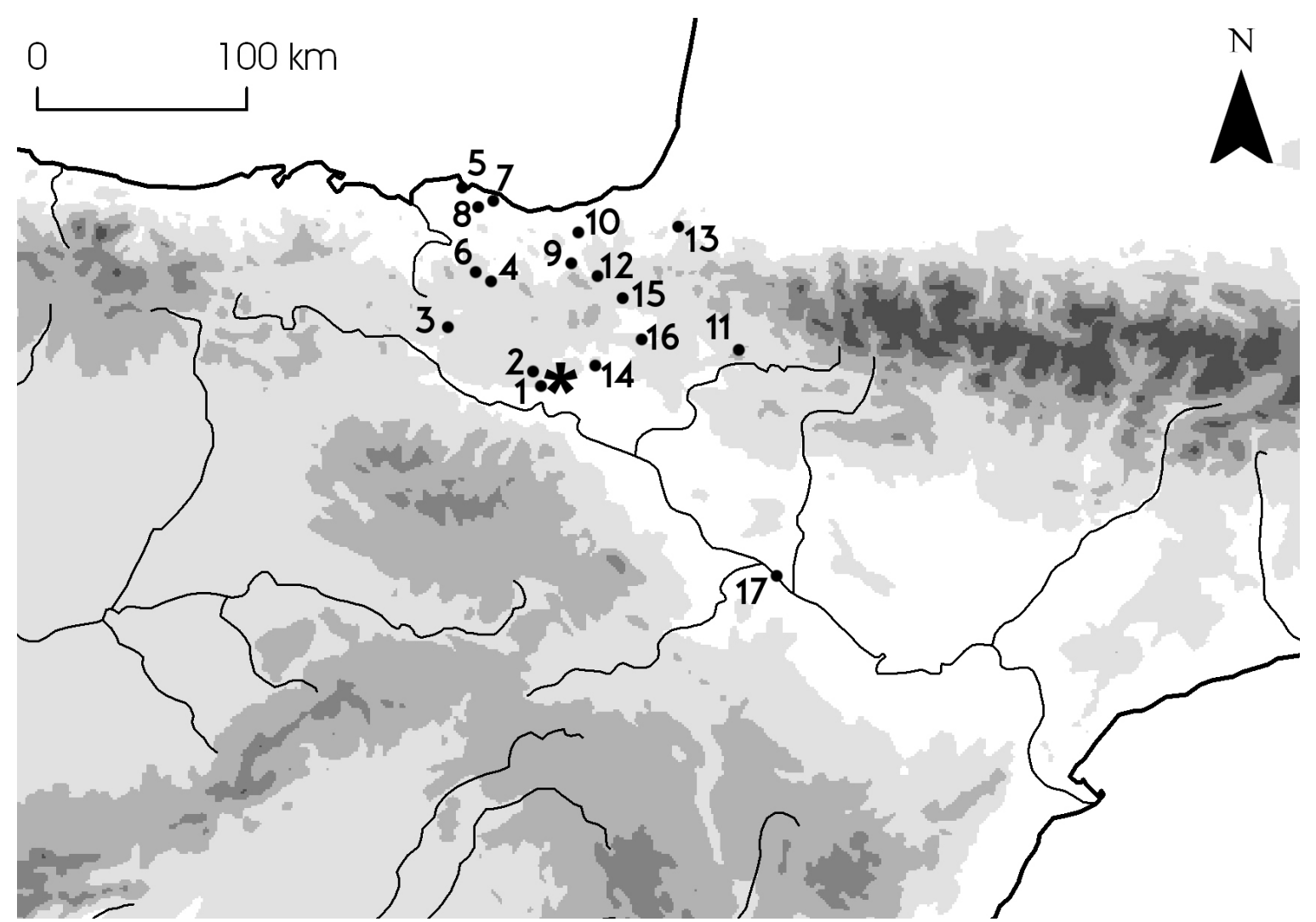

FIG. 5. Sitios arqueológicos con expresiones gráficas postpaleoliticas en el entorno geográfico de dolmen del Alto de la Huesera (*): 1) San Martin y La Hoya; 2) Las Yurdinas; 3) Socuevas; 4) Errekatxuetako Atxa, Mendigana; 5) Katillotxu V; 6) Kurtzegan; 7) Goikolau; 8) Gastiburu; 9) Jentillarri, Intxusburu, Argonitz y Larrarte; 10) Basagain; 11) Turendo; 12) Erroldan Harria; 13) Soalar; 14) Cortecampo II; 15) Peña del Cantero I-II y Echauri; 16) Peña del Cuarto, Añorbe, Elizarrate, Nequeas y Learza; 17) Alto de la Cruz.

o simbólicos, para unos interpretables como "tablero de damero", para otros como elementos de simbolismo gráfico, se documentan en contextos del Hierro en Gastiburu (Valdés, 2009), La Hoya (Llanos, 2002) y La Custodia (Llanos y Vegas, 2009).

También vinculados a las estructuras de habitación domésticas de un momento final del Bronce o inicios de la Edad del Hierro, destacan los grafismos del Alto de la Cruz y de La Hoya (Maluquer de Motes, 1954; Llanos et al., 2009): formas triangulares o zigzags seriados a veces con rellenos interiores de líneas paralelas o incluso puntos, y formas humanas muy sumarias.

El repaso a las evidencias rupestres postpaleolíticas del sector vasco-navarro permite evidenciar un área geográfica con una variada manifestación de simbolismo gráfico documentado en cueva, abrigo, estructura megalítica -dolmen y menhir-, al aire libre, hoyo sepulcral y contexto habitacional de poblado. En algunos casos existe una vinculación espacial entre grafismo y acción funeraria, si bien no es fácil precisar debido a la reutilización funeraria de los lugares, a la ausencia de dataciones numéricas para el grafismo y a la inexistencia de elementos de vinculación certeros, si la acción gráfica está vinculada al momento fundacional, a la clausura o a un momento temporal intermedio.

Con relación a la cronología del arte postpaleolítico, la precisión de su datación sigue siendo objeto de debate. En este contexto de avance e incertidumbre, 
el área de estudio no es ajena a las limitaciones, y por ello las propuestas cronológicas apuntadas deben ser tomadas con cautela, pero a la vez son necesarias para plantear un estado de la cuestión que ciertamente pudiera ser modificado/matizado prontamente.

Las primeras evidencias gráficas postpaleolíticas se corresponderían con los cantos con representación antropomorfa de Mendigana, asociados a un contexto funerario neolítico avanzado y posiblemente de fundación del dolmen. Similar propuesta se ha presentado, a falta de confirmación, para el menhir antropomorfo de Kurtzegan. No es fácil discriminar en la mayor parte de los casos si algunas grafías deben vincularse necesariamente a lo neolítico o ya a las primeras sociedades metalúrgicas calcolíticas, como ocurre con las estelas antropomorfas de Katillotxu v, donde la variedad temática y complejidad técnica del dispositivo iconográfico se acentúa, reconociéndose elementos metálicos como una punta de Palmela. Este momento también pudiera estar representado en el carácter antropomorfo de la estela de Larrarte y en la estela-menhir de Soalar, donde una alabarda muestra claramente la referencia a las sociedades metalúrgicas y el papel de relevancia simbólica - ¿y social?- del hombre armado/guerrero, consecuencia de la mayor complejidad y fragmentación territorial. El mundo antropomorfo -también en Errekatxuetako Atxa con estelas antropomorfasy la presencia de elementos apuntados -en Alto de la Huesera, acaso también como una referencia al mundo de lo bélico/defensivo- son una constante al menos entre hace 4500 y 3500 BP.

Aun no disponiendo de datos certeros sobre la cronología de las pinturas rojas de Las Yurdinas II y Socuevas, parece viable sostener que los grupos calcolíticos, si no antes, desplegaban su iconografía tanto en las estructuras arquitectónicas como en abrigos/cuevas, siendo común en ambos su vinculación espacial a un entorno funerario, aunque debe reconocerse que la iconografía para esta área geográfica no presenta estrechas similitudes gráficas más allá de estar presente el tema humano, sin referencia alguna al mundo del hombre armado/guerrero. Lo evidente, por lo conocido hasta ahora en el sector vasco-navarro, es que la diversidad temática se reduce. Los abrigos de la Peña del Cantero, la cueva de Ciriza y la estela de Echauri, en términos generales, muestran cierta similitud temática, técnica y de implantación con Socuevas y Las Yurdinas II, si bien algunos autores han propuesto la perduración de este tipo de dispositivos gráficos más allá del Calcolítico-Bronce Antiguo, incluso hasta la Edad del Hierro -acaso Peña del Cuarto-. Este hecho implicaría relacionarlos temporalmente con la simplicidad gráfica manifiesta con la estela de la inhumación en hoyo de Cortecampo II, e incluso con el mundo de las cazoletas y elementos similares de Añorbe, Elizarrate, Nequeas, Learza, Beire, Borunda, Jentillarri y Intxusburu para lo que ciertamente la definición cronológica es muy compleja, hasta el punto de no deber descartar su posible edad histórica para, cuando menos, algunos casos.

Sí es segura la adscripción a un momento del Bronce Final o del Hierro Antiguo de los grafismos presentes en estructuras habitacionales de los poblados de La Hoya y el Alto de la Cruz. Su presencia en este contexto asegura una vinculación estrecha entre arte y cotidianidad, más allá de su interpretación simbólica. Similar cronología, o ya propiamente de la Edad del Hierro, debe atribuirse a las 'estelas' de Basagain, Gastiburu, La Hoya y La Custodia.

\section{Conclusión}

La estela decorada del dolmen del Alto de la Huesera, con un dispositivo iconográfico lineal -forma 'acampanada' o de mano- y otros figurativos - dos hojas de puñales de lengüeta-, amplía el repertorio gráfico postpaleolítico y se adscribe a una cronología del Calcolítico Final. Su localización en un contexto arquitectónico monumental funerario pone de relieve el papel del variado equipamiento metalúrgico y su mayor relevancia en los dispositivos iconográficos, que refleja las transformaciones sociales, económicas y territoriales que se estaban produciendo.

$\mathrm{Su}$ valoración en el contexto gráfico cercano permite mostrar, tal y como otros autores han ejemplificado para otras áreas, la diversidad de los 
entornos y contextos de localización, de los temas y de las técnicas del arte postpaleolítico. En el sector vasco-navarro se puede proponer una posible complementariedad de las diferentes manifestaciones gráficas, que deberán complementarse con nuevas evidencias y sus dataciones.

\section{Bibliografía}

Acosta, P. (1968): La pintura rupestre esquemática española. Salamanca: Universidad de Salamanca.

Apellániz, J. M. (1973): Corpus de materiales de las culturas prehistóricas con cerámica de la población de las cavernas del País Vasco Meridional. Munibe supl., 1. San Sebastián: Sociedad de Ciencias Aranzadi.

Aranzadi, T. y Barandiarán, J. M. (1953): "Exploraciones de Prehistoria en las cercanías de Roncesvalles (Auritzberri y Auritz) y en Gorriti y Huici”, Munibe, 5 (2), pp. 74-102.

Armendáriz, J. (1987): "Nuevas cazoletas rupestres en la Navarra Media", Principe de Viana, anejo 48, pp. 183-189.

Armendáriz, R.; Corera, M.; García, C. y Nuin, J. (1987): "Nuevas pinturas esquemáticas en el término de Echauri (Navarra)", Príncipe de Viana, anejo 7, pp. 191-196.

Barandiarán, J. M. (1975): "Exploración de siete dólmenes de la sierra en Ataún-Borunda". En Obras Completas de J. M. Barandiarán. Bilbao: Edit. La Gran Enciclopedia Vasca, t. vII, pp. 383-452.

Barandiarán, J. M.; Aranzadi, T. y Eguren, E. (1918): Exploración de nueve dólmenes en el Aralar guipuzcoano. San Sebastián: Euskalerriaren Alde.

Barandiarán, J. M. y Fernández Medrano, D. (1958): "Excavaciones en Álava", Boletín de la Institución Sancho El Sabio, II (1), pp. 91-180.

Barandiarán, J. M. y Fernández Medrano, D. (1964): "Excavaciones del dolmen de San Martín (Laguardia, Álava)", Boletín de la Institución Sancho el Sabio, 8, pp. 41-66.

Barandiarán, J. M. y Fernández Medrano, D. (1971): "Excavación del dolmen de San Martín (Laguardia)", Investigaciones Arqueológicas en Álava 1957-1968, pp. 147-173.

BASAS, C. (2000/01/02): "El arte esquemático de la cueva de Goikolau (Vizcaya)”, Kobie, xxvı, pp. 109-130.

Beguiristáin, M. A. (1983): "Una laja con pintura esquemática en el Museo de Navarra”, Zephyrus, xxxvI, pp. 149-151.

(C) Universidad de Salamanca
Beguiristáin, M. A. y Jusué, C. (1986): "Petroglifos en Beire, Navarra: una nueva zona con grabados postpaleolíticos", Bajo Aragón Prehistoria, VII-VIII, pp. 265-272.

Beguiristáin, M. A. y Jusué, C. (1987): "Hallazgo de petroglifos en Navarra". En Crónica del XVIII Congreso Arqueológico Nacional. Zaragoza: Univ. Zaragoza, pp. 525-534.

Bello, J. M. (1994): "Grabados, pinturas e ídolos de Dombate, igrupo de Viseu o grupo noroccidental? Aspectos taxonómicos y cronológicos". En Actas del Seminario 'O Megalitismo no centro de Portugal' (Mangualde, 1992). Viseu, pp. 287-304.

Bueno, P. y De Balbín, R. (2003): "Una geografía cultural del arte megalítico ibérico: las supuestas áreas marginales". En De Balbín, R. y Bueno, P. (eds.): El arte prehistórico desde los inicios del siglo XXI. Ribadesella: Asociación de Amigos de Ribadesella, pp. 291-313.

Bueno, P. y De Balbín, R. (2007/2009): "Katillotxu v. Un programa gráfico integral”. En López Quintana, J. C. (ed.): "El conjunto monumental de Katillotxu (Mundaka): una mirada al Megalitismo cantábrico", Illunzar, 7, pp. 127-138.

Bueno, P.; De Balbín, R. y Barroso, R. (2005): "La estela armada de Soalar. Valle de Baztán (Navarra)", Trabajos de Arqueología Navarra, 18, pp. 5-40.

Bueno, P.; De Balbín, R. y Barroso, R. (2008): "Models of integration of rock art and megalith builders in the International Tagus". En Bueno, P. y De BaLBín, R.: Graphical markers \& megalith builders in the International Tagus, Iberian Peninsula. BAR Int. Ser., 1765. Oxford: Archaeopress, pp. 5-15.

Bueno, P.; De Balbín, R.; Barroso, R.; López Quintana, J. C. y Guenaga, A. (2009a): "Frontières et art mégalithique. Une perspective depuis le monde pyrenéen", L'Anthropologie, 113, pp. 882-929.

Bueno, P.; De Balbín, R.; Barroso, R.; López Quintana, J. C. y Guenaga, A. (2009b): “Entre fronteras. Perspectivas de análisis del arte megalítico en el norte de la Península Ibérica”, Illunzar, 7, pp. 39-62.

De Balbín, R. (1989): "Arte megalítico y esquemático en el norte de la Península Ibérica”. En González Morales, M. R. (ed.): Cien años después de Sautuola. Santander: Diput. Regional de Cantabria, pp. 15-98.

De Blas, M. A. (1997): "El arte megalítico en el territorio cantábrico: un fenómeno entre la nitidez y la ambigüedad". En Actas III Congreso Internacional de Arte Megalítico. Brigantium, 10, pp. 69-89.

Delibes, G. y Rojo, M. (1988): "En torno al origen del foco megalítico del Oriente de la Meseta, de nuevo el 
sepulcro de Cubillejo de Lara", Boletín del Seminario de Estudios de Arte y Arqueología, 54, pp. 5-21.

DíAz, Y. (1993): El arte rupestre esquemático en Cantabria. Una revisión crítica. Santander: Univ. Cantabria.

FARIÑA, J. (1966): "Un enterramiento en la Sierra de Cantabria (Álava)", Estudios de Arqueología Alavesa, 1, p. 160.

Fernández Crespo, T. y De la Rúa, C. (2015): “Demographic evidence of selective burial in megalithic graves of northern Spain", Journal of Archaeological Science, 53, pp. 604-617.

Fernández-Eraso, J. (2003): Las Yurdinas II: Un depósito funerario entre finales del IV y comienzos del III milenio BC. Monografías de Yacimientos Alaveses, 8. Vitoria: Diput. Foral de Álava.

Fernández-Eraso, J. y Mujika-Alustiza, J. A. (2011): "Dólmenes de la Rioja Alavesa: El Montecillo (Villabuena de Álava), Chabola de la Hechicera (Elvillar) y Alto de la Huesera (Laguardia)", Arkeoikuska, 10, pp. 164-174.

Fernández-Eraso, J. y Mujika-Alustiza, J. A. (2012): "Dólmenes de la Rioja Alavesa: Chabola de la Hechicera (Elvillar) y Alto de la Huesera (Laguardia)", Arkeoikuska, 11, pp. 207-212.

Fernández-Eraso, J. y Mujika-Alustiza, J. A. (2013): "La estación megalítica de la Rioja Alavesa: cronología, orígenes y ciclos de utilización", Zephyrus, LXXI, pp. 89-106.

Fernández-Eraso, J. y Mujika-Alustiza, J. A. (2014): "Dolmen del Alto de la Huesera", Arkeoikuska, 13, pp. 99-103.

Fernández-Eraso, J.; Mujika-Alustiza, J. A. y FerNÁNDEZ Crespo, M. T. (2015): "Sobre la cronología de los ídolos-espátula del dolmen de San Martín (Laguardia-Álava)". En Homenaje a R. de Balbin Behrmann. ARPI 03 Extra, pp. 257-271.

Fernández Medrano, D. (1948): "Descubrimientos prehistóricos en la zona de Laguardia (Álava)", Ikuska, 10-13, pp. 77-78.

Galilea, F. (2009): "Datación por C14 del dolmen de San Martín (Laguardia, Álava). Dataciones actuales de excavaciones antiguas", Estudios de Arqueología Alavesa, 24, pp. 131-146.

García-Diez, M. y González, M. R. (2003): “En torno al llamado 'arte esquemático-abstracto': a propósito de unas fechas de Covalanas (Ramales de la Victoria, Cantabria)", Veleia, 20, pp. 227-241.

García-Diez, M. y Hortolá, P. (2003): "Grafismo pintado en el abrigo de Las Yurdinas II". En FernánDeZ-Eraso, J. (coord.): Las Yurdinas II (Peñacerradal
Urizaharra, Álava): un depósito funerario entre finales del IV y comienzos del III milenio BC. Memorias de Yacimientos Alaveses, 8. Vitoria: Diput. Foral Álava, pp. 149-162.

Gómez Barrera, J. A. (1992): Grabados rupestres post-paleoliticos del Alto Duero. Soria: Caja Duero.

ItUrRalde y Suit, J. (1911): "Monumentos Megalíticos de Navarra", Boletin de la Real Academia de la Historia, LVIII (III), pp. 197-215.

Llanos, A. (1966): "Resumen tipológico del arte esquemático en el País Vasco-Navarro", Estudios de Arqueologia Alavesa, 1, pp. 149-158.

Llanos, A. (1977): "Avance a un planteamiento sobre el arte rupestre esquemático-abstracto en el Norte de España”. En Actas XIV Congreso Nacional de Arqueologia (Vitoria, 1975). Zaragoza: Univ. Zaragoza, pp. 645-648.

Llanos, A. (2002): "Tableros de juego en el patrimonio arqueológico de Álava”, Estudios de Arqueología Alavesa, 19, pp. 191-196.

LLanos, A. (2007): "El conjunto de pinturas rupestres de Portillo Lerón, Parque de Valderejo (Lahoz, Álava)", Estudios de Arqueología Alavesa, 24, pp. 275-295.

Llanos, A.; Armendáriz, J.; Castiella, A.; Peñalver, X.; Sáenz de Urturi, P. y Unzueta, M. (2009): "La Edad del Hierro en el Cantábrico oriental y su entorno". En Actas Medio siglo de Arqueología en el Cantábrico oriental y su entorno. Vitoria: Instituto Alavés de Arqueología, pp. 201-344.

Llanos, A. y Vegas, J. I. (2009): "Cavidad de Socuevas de San Miguel, Álava. Sus pinturas y grabados”, Estudios de Arqueología Alavesa, 24, pp. 225-274.

López Quintana, J. C. (2015): "Dólmenes, cistas y menhires en la estación megalítica de Gorbeia (País Vasco): distribución geográfica y secuencia funeraria”. En Death as Archaeology of Transition: Thoughts and Materials. BAR Int. Ser., 2708. Oxford: Archaeopress, pp. 197-219.

López Quintana, J. C. y Guenaga, A. (2007/2009): "El dolmen de Katillotxu v (Mundaka, Bizkaia): arquitectura y secuencia estratigráfica de un monumento megalítico decorado". En López Quintana, J. C. (ed.): El conjunto monumental de Katillotxu (Mundaka): una mirada al Megalitismo cantábrico. Illunzar, 7, pp. 87-125.

López Quintana, J. C.; Guenaga, A.; Bueno, P. y De Balbín, R. (2010): "El código funerario megalítico en Bizkaia: estelas y estatuas en dólmenes de Urdabai y Gorbeia”, Munibe, supl. 32, pp. 472-486. 
MaluQuer de Motes, J. (1954): El yacimiento hallstático de Cortes de Navarra. Pamplona: Institución Príncipe de Viana.

Mendoza, F. (1922): "Un cementerio antiguo en la Borunda", Boletín de la Comisión de Monumentos Históricos y Artísticos de Navarra, XIII, pp. 59-65.

Monreal, A. (1977): Carta arqueológica del Señorio de Learza (Navarra). Pamplona: Institución Príncipe de Viana.

Mujika-Alustiza, J. A. y Armendáriz, A. (1991): “Excavaciones en la estación megalítica de Murumendi (Beasain, Guipúzcoa)", Munibe, 43, pp. 105-165.

Narvarte, N. (2005): Gestión funeraria dolménica en la cuenca Alta y Media del Ebro: fases de ocupación y clausuras. Historia-Arqueología, 16. Logrońo: Instituto de Estudios Riojanos.

Nuin, J. (1988/1989): "Nuevas aportaciones para el conocimiento del arte esquemático en el valle de Etxauri y una aproximación a su interpretación”, Príncipe de Viana, anejo 14, pp. 97-103.

Peñalver, X. (2009): "Estela decorada del poblado protohistórico de Basagain (Anoeta, Guipuzkoa)", Veleia, 27, pp. 43-53.
Ramos, M. (2007): "Cortecampo ir (Los Arcos) y Osaleta (Lorca, Valle de Yerri). Sepulturas descubiertas en las obras de la autovía del Camino". En La Tierra te sea leve. Arqueología de la muerte en Navarra. Pamplona: Institución Príncipe de Viana, pp. 93-96.

Rodríguez de la Esperanza, M. J. (2005): Metalurgia y metalúrgicos en el Valle del Ebro (c. 2900-1500 cal. AC). Bibliotheca Archaeologica Hispana, 24. Madrid: RAH-Institución Fernando el Católico.

Santesteban, I. (1969): "Primeros vestigios de pintura rupestre en Navarra”, Principe de Viana, 112-113, p. 327.

Santesteban, I. (1971): "Pinturas rupestres en Navarra”, Principe de Viana, 124-125, pp. 263-265.

Shee, E. (1981): The megalithic art of Western Europe. Oxford: Clarendon Press.

VALDÉs, L. (2009): El santuario vasco de la Edad del Hierro y el territorio Cariete del oppidum de Marueleza. Madrid: RAH. 